\title{
Study on Hospital Medical Information Engineering
}

\author{
Na Wang ${ }^{1}$ and Qun $\mathrm{Li}^{2, a, *}$ \\ ${ }^{1}$ Department of Anesthesiology, First Hospital of Jilin University, Changchun, China \\ ${ }^{2}$ Department of Thyroid Surgery, First Hospital of Jilin University, Changchun, China \\ ${ }^{*}$ Corresponding author: Qun Li
}

\begin{abstract}
On the base of the current status of hospital medical information engineering, this paper analyzes some major problems existing in computer hardware, and puts forward some plans and reform measures in connection with the characteristics of medical information engineering. Because the application of electronic information engineering in hospitals is perfect and comprehensive, and there is no corresponding management training, so that the management personnel do not have the information technology and skills required by the application of electronic information engineering, the training of relevant personnel should be strengthened.
\end{abstract}

\section{Introduction}

Medical information is a science of information in medical field. The rule of information in medicine is the main research content and application method, with modern computer and information technology as the main tool, in order to solve medical staff [1]. In dealing with various problems in the process of medical information as the main research goal of an emerging discipline, it is a cross discipline between medicine and informatics. International medical information experts pointed out: "medical information consists of two aspects: information processing and communication theory and application, and the two aspects deal with the knowledge and experience acquired in the process of medical and health care" [2]. With the deep application of information technology, medical colleges and universities abroad, including western medicine and traditional Chinese medicine, have opened medical information engineering related majors.

Computer technology is a major component of medical information, involving network communication technology, database technology, wireless sensing technology, artificial intelligence and other fields of computer science, curriculum can be divided into software curriculum group and hardware curriculum group [3].

\section{Problems existing in the medical information engineering}

\section{1 lgnoring of medical information engineering}

By the traditional management mode, and thought some administrative personnel in the practical work are more

\footnotetext{
a Corresponding author: lilyly12345@163.com
}

likely than traditional methods, this phenomenon cannot be eradicated, immediately if it is forced to change will cause the staff cannot adapt to the new management mode, it adds unnecessary trouble, in the management of influence the working efficiency [4].

In the final analysis, these problems are caused by the inadequacy of the hospital's application of electronic information engineering and the lack of corresponding management training, which make the managers not equipped with the information technology and skills required by the application of electronic information engineering [5].

\subsection{Insufficient information sharing between departments}

Each department in the hospital belongs to an independent unit, according to the division of responsibilities. The link between departments is not close, so it needs each department in the administrative management to integrate all kinds of information [6]. This decentralized information environment is easy to bring huge problem for the administrative management. Repeated information between the departments will happen, it will affect the actual application effect of the electronic information engineering [7].

\subsection{Incompatibility between management requirements and electronic information engineering system}

At present the applied electronic information engineering is mainly purchased from software company, so it is inevitable in practical software development company that understanding of medical service system is not 
enough [8]. It will inevitably happen in the process of system application to cost a lot of time and energy to fit the requirements of the hospital management. Serious errors still may be caused in the administrative management [9].

\section{Countermeasures to improve the application of electronic information engineering in hospital administration}

\subsection{Establishing a long-term goal}

As an important part of hospital informatization, electronic information engineering must ensure that it has specific goals and sufficient funds to support its development. Hospital managers must pay more attention to it, define long-term development goals, and combine system design with hospital development goals. At the same time, the hospital should increase the capital investment in the construction of the information system, and not ignore the long-term impact of the information system because of the lack of short-term benefits [10].

\subsection{Improving information sharing}

Hospital administrative departments should not only pay attention to the electronic information engineering of each department, but also strengthen the contact between departments, and make use of the network to make the independent management system become an organic whole [11]. Through sufficient communication between departments, the original management process is changed and reorganized, so that the information can be shared smoothly and the work process can be simplified, and the management staff can be truly liberated from the complex manual labor.

\subsection{Giving right to information engineering technicians}

Hospital leaders should correctly recognize that technical personnel are the designers of information planning and the main body of hospital informatization construction. We should give full play to their enthusiasm, guide them to participate in the overall planning of electronic information engineering construction, fully respect the opinions of information engineering and technical personnel in equipment procurement and bidding, machine room construction and other major investment projects, and promote them to realize their own value, work hard to study the business, and adapt to the needs of construction and development. In addition, military hospitals can also make full use of the resettlement policy for demobilized soldiers, establish elimination mechanism, and timely introduce and retain talents [12].

In addition, the good medical teaching and research platform of the hospital can be used to give proper preference to the scientific research policy and teaching task arrangement, increase the investment in medical information engineering scientific research projects, exercise the teaching and teaching ability of information engineering personnel, and create the cultural atmosphere of digital hospital, so as to promote the growth of talents.

\subsection{Optimizing the structure of information engineering technicians}

With the advent of digital hospitals, the degree of hospital informatization is getting higher and higher. Large hospitals are not only a huge and complex system providing medical services, but also a database constantly generating ever-changing data and accumulating various information [13]. Therefore, electronic information engineering is necessary to train leaders who can be responsible for the overall planning, construction, guidance of network, operation and maintenance of the hospital information system, be good at managing information engineering and technical personnel, and be able to assist, supervise, guide and coordinate the management of important database, so as to adapt to the rapid development of IT technology.

In the future, will also improve their education level, foreign language level, business skills, scientific research and teaching ability, by degree, short-term training and foreign academic exchanges, we organized scientific research project, the development of software, and published many high quality academic papers and developed with independent intellectual property rights of software for the inspection way, strive to cultivate a have some impact on information network center academic leaders. reproduction, pasted in the appropriate place in the text.

\section{Conclusion}

Medical information engineering is the information technology and health care knowledge development emerging cross compound professional depth fusion, the specialty is a composite cross type, involving medical basic knowledge, basic knowledge of management, information technology professional knowledge, professional knowledge of hospital information system, such as module, talent standards formulated by each are not identical, so the current comparison pay attention to talent cultivation of creative knowledge more need to strengthen.

Training target of medical information engineering talents is to have medical background and solid information engineering basic knowledge of management the basic theory and practical skills, have good professional ethics, strong interpersonal communication ability and the innovation, entrepreneurial spirit, to engage in medical and health information system application, maintenance, management, design and development work of medical information engineering talents.

\section{References}

1. Vakkari P. Information seeking in context: a challenging metatheory. Information seeking in 
context: proceedings of an International Conference on Research in Information Needs, 1997.

2. T.D. Wilson. Information behaviour: An interdisciplinary perspective. Information Processing and Management, 1997 (4).

3. Ingwersen P. Cognitive perspectives of information retrieval interaction: elements of a cognitive IR theory. Journal of Documentation, 1996.

4. Harris Peter R, Sillence Elizabeth, Briggs Pam. Perceived threat and corroboration: key factors that improve a predictive model of trust in internet-based health information and advice. Journal of medical Internet research, 2011.

5. B. Dervin. Users as Research Inventions: How Research Categories perpetuate Inequities. Journal of Communication, 1989.

6. Amanda Spink, Charles Cole. J. Human information behavior: Integrating diverse approaches and information use. Am. Soc. Inf. Sci., 2005 (1).
7. T. D. Wilson. Human Information Behavior Informing Science, 2000.

8. Ingwersen P, Jrvelin K. The Turn: Integration of Information Seeking and Retrieval in Context, 2006.

9. Behrens. A conceptual analysis and historical overview of information literacy. Shirley J. College and Research Libraries, 1994.

10. Stanford's Key to Information Literacy. The Board of Trustees of the Leland Stanford Junior University. http://skil.stanford.edu/intro/index.html, 2011.

11. Marlene Asselin. Improving literacy education through professional study: the leadership role of the teacher-librarian. Teacher Librarian, 2003.

12. Luigi T. De Luca, Propulsion physics EDP Sciences, Les Ulis, 2009.

13. Sagi Filin, Norbert Pfeifer. Segmentation of airborne laser scanning data using a slope adaptive neighborhood. ISPRS Journal of Photogrammetry and Remote Sensing, 2005 (2). 